Western University

Scholarship@Western

FIMS Publications

Information \& Media Studies (FIMS) Faculty

2014

\title{
Beyond obscenity: An analysis of sexual discourse in LIS educational texts
}

Heather Hill

Western University, hhill6@uwo.ca

Marni Harrington

The University of Western Ontario, mharring@uwo.ca

Follow this and additional works at: https://ir.lib.uwo.ca/fimspub

Part of the Library and Information Science Commons

Citation of this paper:

Hill, H. and Harrington, M. (2014) 'Beyond obscenity: An analysis of sexual discourse in LIS educational texts', Journal of Documentation, 70(1), pp. 62-73. doi: 10.1108/jd-11-2012-0150. 


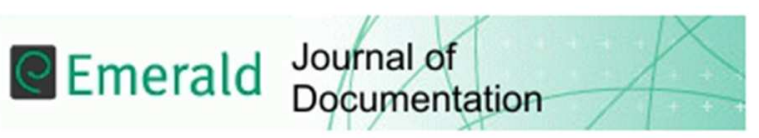

\section{Beyond obscenity: An analysis of sexual discourse in LIS educational texts}

\begin{tabular}{|r|l|}
\hline Journal: & Journal of Documentation \\
\hline Manuscript ID: & JD-11-2012-0150.R1 \\
\hline Manuscript Type: & Article \\
\hline Keywords: & Collection development, Censorship, Ethics \\
\hline \multicolumn{3}{c}{} \\
\\
\multicolumn{3}{c}{$\begin{array}{r}\text { SCHOLARONE } \\
\text { Manuscripts }\end{array}$} \\
\end{tabular}




\section{Beyond obscenity: An analysis of sexual discourse in LIS educational texts}

\section{Introduction}

The popularity of E. L. James' Fifty Shades of Grey trilogy with the mainstream reading public represents a unique event where an erotic novel series became openly read and widely discussed. It is inarguable that the trilogy has gained far more public interest and public acceptance than any other erotica. The paperback release of the first novel surpassed sales of the Twilight paperbacks (Bentley, 2012) which is particularly interesting as Fifty Shades of Grey began its existence as Twilight fanfiction. James' trilogy is sold in warehouse clubs not normally known for selling erotica, book clubs advertise it, it has been the catalyst for new publishing within the genre, and unrelated businesses create advertising puns with the title. For example, a men's clothier advertised its "fifty shades of grey suits."

An examination of WorldCat (November, 2012) shows that more than 2000 libraries have added the English-language Fifty Shades of Grey to their collections with another 450 libraries carrying the title in large print. The main collectors are academic and public libraries, but in some public libraries the series was not purchased, because, as one library director stated, "We don't collect porn" (ABC News). Controversy arose, not over the book, but over some libraries' refusal to bring such a high-demand title into the collection. After much negative publicity the works were added to some of those collections, but the strong resistance to the series brings to mind questions of self-censorship.

Censorship and controversial materials are issues that are fundamental to library and information science (LIS). The guiding principles of the profession, in the form of the American Library Association's (ALA) Bill of Rights (American Library Association, 1996) as well as other professional values statements, require the combating of censorship and the provision of multiple viewpoints on controversial issues. As the controversy over Fifty Shades of Grey demonstrates, it can be difficult to remain neutral on certain issues, particularly those dealing with sex. Without dispute, sex has become more visible and explicit as demonstrated by the increased access to representations of sex and sexuality, and products and services of a sexual nature (McNair, 2002). At the same time, topics related to sex are a leading basis for challenges in library collections (Library Research Service, 2012, 2011, 2010, 2009).

To be grounded in the ethics of the profession, selecting materials for a library collection requires tackling challenging topics. Learning about collection development for any library requires an understanding of controversial topics and materials. Adequately addressing this area supports the basic principles of the profession and provides a safe space in which to consider controversial materials, particularly in regard to frequently-challenged materials of a sexual focus. What kind of discourse is being encouraged within the safe, educational spaces of LIS programs? 
This paper analyzes how controversial materials of a sexual nature are presented in the texts used in LIS education programs in North America. Critically examining how these topics are portrayed in LIS texts explores issues of professional ethics related to self-censorship and will provide a basis for a broader critical discussion of ethics within the field.

\section{Literature Review}

The literature examining pornography, erotica, and other sexually themed materials in LIS focuses on examining collections, cataloguing and classification, and the social and cultural pressures librarians encounter. Fully framing the current project requires an understanding of the shift in the role of the librarian from one of "censor" to one of "defender of intellectual freedom" and an understanding of how controversial materials, writ large, have been explored.

\subsection{Research on the shift from censorship to selection}

"Books that...teach how to sin and how pleasant sin is, sometimes with and sometimes without the added sauce of impropriety, are increasingly popular... Thank Heaven they do not tempt the librarian" (Charles Bostwick, 1908, as quoted in the Intellectual Freedom Manual, 2002, p. 6).

In the ensuing years after Bostwick's ALA inaugural presidency speech, little changed in librarian attitudes towards censorship, as demonstrated in Feipel's (1922) work. He found that although social change was increasing the availability of controversial materials of a sexual nature, cultural consensus kept it out of mainstream society and out of libraries. By the 1950s, clear distinctions were attempted between censorship and selection with Asheim's (1953) piece Not Censorship But Selection. Anti-censorship sentiments did not replace censorship in the professional discourse until the 1960s.

The growing acceptance of sex in modern society and the production of materials dealing with sexual topics increased in works of fiction and quickly moved to non-fiction (Robinson, 1977). The library profession also began to disregard some of the social restrictions of the past and more liberally collected works with sexual themes. With AIDS, sex education in schools, and homosexuality becoming mainstream issues in the 1980s, talking and writing about sex was less marginalized (Cornog, 1991). Libraries were compelled to address controversial topics to remain significant. “... when library purchases and access policies are dominated by the traditionalist reverence for silence about sex, the library can all too easily become merely irrelevant to a modern world in which talk and writing about sex are the norm." (Cornog, 1991, p. 27).

Current discourse around pornography and erotica is usually in terms of harmful effects (Attwood, 2002) and issues of librarian self-censorship continue (Crook, 2001; Moody, 2005). 
Along with personal challenges and changing social mores, the legal challenges librarians face in addressing sexual materials has continued to be of interest (Morgan, 2001; McLean, 2003).

\subsection{Attitudes of librarians about controversial materials and libraries}

The literature examining the selection of controversial materials, particularly those dealing with sex, and the attitudes of librarians in their practice is sparse. Controversial titles are challenging for all types of libraries. Public and school libraries receive the most attention on the topic of controversial materials, but no library is immune from issues of self-censorship. Academic (Pope, 1974), special (Hurych \& Glenn, 1987; Siegal, 2007), public (Fiske, 1959; Broderick, 1962; Moon, 1962; Pope, 1974; Steinfirst, 1980), and school (Pope, 1974; Rickman, 2007) library workers have all had difficulties handling controversial materials. In medical and health settings, where one would expect staff would be prepared and able to discuss controversial topics, Siegel (2007) found health librarians to be minimally comfortable discussing sexual issues with patrons. Hurych and Glenn (1987) found that $20 \%$ of medical librarians surveyed agreed with the statement, "materials should not be included in the collection if inconsistent with librarian's personal beliefs."

Titles that are listed or deemed controversial are less likely to be added to collections (Fiske, 1959; Busha, 1972; Steinfirst, 1980 Hurych \& Glenn's, 1987; Curry, 1994; Sens et al. 2010), but the presence of multiple, favourable reviews increases the likelihood that something will be selected (Serebnick, 1979; Watson \& Snider, 1981). Resources such as Playboy are held to a different standard than other library materials (e.g., financial magazines and children's materials) that have similar theft and mutilation rates (Cornog, 1991). An anecdotal example of librarians' attitudes with sexually-explicit material reinforces the above research. Recently, at a large Canadian university library, a librarian was offered a 43-year run of a Playboy collection and refused to consider the donation because she did not want to offend her subject-specific community (Harrington, 2011). In summary, all of these findings demonstrate a discontinuity between library practice and library principles.

\subsection{Research into collection development tools and LIS education texts}

Self-censorship may go beyond just collection development issues; there may also be a silencing of the research on controversial materials. The profession, overall, voices the duty to protest censorship, but the lens is rarely directed inward and studies that have been completed quickly fade from the literature. Fiske's (1959) significant research on controversial materials investigated censorship as a possible learned behaviour in library school. Findings indicated that librarians were not defending intellectual freedom; rather, they were active censors. Thirteen years later Busha (1972) looked for traces of Fiske's study in materials that support selection practices, the materials assigned to LIS students through course reserves, and circulating collections and found very few references to Fiske's important study. 
Beyond looking at the profession's own biases towards controversial topics, there have been few attempts in LIS to focus outward on the broader culture. In one of the few modern studies examining pornography in LIS, Dilevko and Gottlieb (2002) provide a broad analysis including an overview of the pornography business, the categorization of materials used by stores and catalogues that sell pornography, and how these categories might be adjusted for the library environments. They note that community standards shift over time and are dependent on class and other social structures, therefore definitions for sexual materials are impermanent and subjective. They further argue that as the pornography industry grows it is becoming part of mainstream culture. Because of this growth, pornography will become increasingly of interest to researchers, particularly in such areas as popular culture studies and anthropology, and is thus something to be addressed in library collections.

Comprehensive analyses of controversial materials, particularly those related to sex, are few within LIS, but there are indications that library workers with professional training and affiliations with professional organizations are less likely censor (Fiske, 1959; Rickman, 2007). This leads to the conclusion that controversial materials are, in some way, addressed in LIS programs. The current research marks the first effort to examine the intersection of the LIS education literature and sexually-explicit topics.

\section{Current Research and Methodology}

This project is informed by Michel Foucault's perspective on discourse and power as outlined in his lecture "Discourse on Language" particularly his understanding of education. Education "follows the well-trodden battle lines of social conflict. Every educational system is a political means of maintaining or of modifying the appropriation of discourse" (Foucault, 1972, p. 227). It is the contention here that cultural discomfort with sexual topics stymies discourse in the profession and impedes treating this topic in a manner consistent with professional ethics.

\subsection{Research questions}

The primary research question addressed in this research is what is the discourse surrounding controversial materials of a sexual nature, in LIS education materials? Specifically, the following questions are addressed:

1. Are sexual materials given coverage in LIS texts?

2. When topics of a sexual nature are included, is a nuanced definition or usage provided? More explicitly, are sexual topics given an accurate definition (obscenity) or is there an acknowledgement of the contested nature of defining some terms (pornography)?

3. Has the representation of sexual materials changed over time?

\subsection{Method}


The focus of this research is the teaching literature and the literature written for an audience of practitioners. The materials studied were selected from the library collection of a long-standing, ALA-accredited LIS program. Keyword and subject heading searches of the extensive collection provided the list of titles for analysis. Search queries included such terms as 'collection development,' 'collection management', 'reference,' and 'libraries-censorship.' Both researchers created concept maps and searched individually. The two lists were combined to ensure that no relevant titles were missed. Texts on intellectual freedom, collection development, and reference works consisting of encyclopaedias, glossaries, dictionaries, handbooks and manuals were included for analysis. Both current and historical texts were included and most were available in print format.

The table of contents, indices, glossaries, entries, sections, and chapter headings of each text were examined for specific trigger elements. Key terms of focus were sex, obscenity, pornography, erotica, curiosa, and facetiae (and their derivations). Curiosa and facetiae were not in the original keyword list, but their prevalence within the texts necessitated their addition. In addition, searches were made for controversial materials and censorship where the terms of interest are often subsumed. As this research was centered around pornography, erotica, and similar terms, questions on sex dealing with health, hygiene, and disease were out of scope.

The majority of texts analyzed for this study were published in the United States (U.S.)and hence have an American bias. This inherent bias may limit the applicability of the results outside of North America. But the North American focus of this research and the dominance of U.S. published materials necessitated the use of American legal terminology and a reliance on American Library Association guidelines. All definitions and usages were analyzed and compared to key exemplar definitions using the U.S. legal definition of obscenity (per the Roth and Miller test) and Kent's (1968) definition of erotica.

Definitions were categorized into one of four types: poorly defined with derogatory remarks attached to the keywords; mediocre treatment of the topic that did not adequately define the keywords but had some redeeming qualities; neutral works that provided fair and balanced coverage reflecting the legal definitions of the keywords and library ethical standards of its time; or works that contained none of the key terms.

\section{Findings}

Using the methodology outlined above, 85 texts, published between 1943 and 2012 were gathered for analysis. Table 1 depicts the breakdown between decade of publication and type of text analyzed. The results are presented by responding to each research question under investigation. 


\subsection{Research question - Are sexual materials given coverage in LIS texts?}

As shown in Table 2, forty-nine (58\%) of the texts addressed or defined, in some way, the key terms. These texts included a variety of materials on intellectual freedom $(n=14)$, collection development $(n=11)$, and reference works like glossaries $(n=10)$, dictionaries $(n=8)$, and encyclopaedias $(n=6)$.

The remaining thirty-six (42\%) texts included no reference to any of the five key terms of interest. Published between 1964 and 2012, these were predominantly collection development texts $(n=30)$ but also included three encyclopaedias, two dictionaries and one text on intellectual freedom.

The 30 collection development texts referenced above represent $73 \%$ of the collection development texts examined. It is significant that $73 \%$ of the collection development texts examined make no reference to any sexual themes. These texts only discuss censorship in broad strokes. While the collection development texts show a disturbing trend of not addressing sexual topics, the remaining six texts seem to be outliers. It is puzzling that the dictionaries and encyclopaedias have no entries for the five key terms, as the terms were expected to be discussed within the scope of the works. And finally, what is truly strange is an intellectual freedom text that discusses banned books, yet makes no substantial reference to any of the five key terms.

Insert Table 2 here

\subsection{Research Question - When topics of a sexual nature are included, is a nuanced definition or usage provided?}

As expected, the intellectual freedom texts provided nuanced definitions and usages for the terms of interest and they also acknowledge the contested nature of defining such terms. Beyond this particular category of text, only two other works clearly articulate the difficulties of defining these terms. It is this recognition of "difficult to define" that must be acknowledged to critically engage with controversial works.

Kent's entry on erotica in the Encyclopedia of Library and Information Science (1968) sets the standard for a full articulation on the difficulties of working with texts of a sexual nature. His twenty page entry covers a broad range of subtopics including the difficulties of definition, helpful assistance in developing a pornography collection, and a specific focus on gay literature.

Whatever definition is attempted of pornography...will invariably conflict with the definition of erotica. If erotica is all sexually oriented material, then pornography is a special kind. Much that is labeled pornography is, in effect, erotica and not pornographic at all. The word pornography is often employed as a kind of pejorative meant to label material with which the reviewer dislikes. Just as poor 
verse is called doggerel, and a poor painting is called a daub, so erotica disliked by the reviewer will be called pornography.

Kent, pg. 165, 1968

Foerstel's Free Expression and Censorship in America: An Encyclopedia (1997) discusses the complexities involved in attempting to differentiate erotica, pornography, and obscenity. In a lengthy discussion referencing multiple literatures beyond LIS, he reduces the difficulties as thus, "What turns me on is erotic. What turns you on is pornographic" (pg. 70). Beyond these few texts pornography and erotica are placed in the same box with no subdivisions for subgenre such as feminist, gay, or lesbian pornography.

Obscenity, facetiae, and curiosa were all likely to be defined or used in an objective manner. Obscenity, as stated above, has a legal definition and, as such, many of the texts described the Miller Test. Curiosa and facetiae are significantly historical terms whose definitions are standardized at this point. Even with standard definitions for historical terms and a legal definition for obscenity, three texts provided inaccurate definitions for obscenity and two provided negative definitions for facetiae.

Pornography and erotica were the most likely terms to be defined negatively. Most often pornography is not distinguished in any way from erotica and both are equated with obscenity. Both terms are laden with the labels such as "obscene" and "indecent", but there are differences in the way some texts treat the terms.

For erotica the adjective "indecent" appears in the definitions in multiple sources with no accompanying definition for the word indecent. In addition, two sources start with a seemingly objective definition for erotica, but then make it seem as if the genre is no longer active. As an example, one text begins defining erotica as "works intended to stimulate sexual interests" and then continues by discussing that examples can be found in rare book collections. The only example of the genre, in any of the texts examined, is a reference to Fanny Hill or Memoirs of a Woman of Pleasure, a 264 year old text. There is no room in these definitions for erotica as a currently active and popular genre.

Overall, the definitions are predominately simplistic and pejorative when discussing sexual topics. Few of the terms of interest here have uncontested definitions. In fact, it can be argued that since 'obscenity' is the only term with a legal definition that it is the only one of focus that has a standard definition. For terms like 'pornography' and 'erotica' any meaningful effort at defining them would require an acknowledgement of the cultural constraints and biases inherent in doing so. Even with such acknowledgement, creating an uncontested definition would be difficult. Attwood noted the difficulties inherent in attempting to define a term like 'pornography.' "Definitions of 'pornography' produce rather than discover porn texts and, in 
fact, often reveal less about those texts than they do about fears of their audiences' susceptibility to be aroused, corrupted and depraved" (Attwood, 2006, p. 94-95).

\subsection{Research question - Has the representation of sexual materials in LIS texts changed over time?}

There were two routes used to examine the almost 70 years worth of texts. First, texts with multiple editions were studied for additions, deletions or change in tone of sections containing keywords from one edition to the next. Second, all of the texts were separated by eras and examined for any patterns.

Ten texts had multiple editions. These included editions of 4 encyclopaedias, 2 glossaries, 2 texts on collection development, one dictionary, and one text on intellectual freedom. In all, there were 28 texts available for this analysis. Within the narrow lens of texts with multiple editions, there is no set pattern of representation of sexual topics.

In three texts, the definitions remain the same throughout. For two of those texts the same poor definitions are used throughout. The third, the Intellectual Freedom Manual, provided a balanced approach over time to all of the sexually-related themes. Paradoxically, in the editions of two texts (an encyclopaedia and collection development text) none of the editions discuss sexually explicit topics.

In four texts the treatment of sexual topics becomes pejorative over time. For example, older editions of one work did not define pornography. In the latest edition, pornography has been added and is defined as "works depicting sexual conduct in an offensive way." The question of 'offensive to whom?' is not answered here. Lastly, in a series of encyclopaedias, an older edition has a detailed entry for erotica that includes a nuanced discussion of pornography, but successive editions have no entries to any of the terms of interest.

While there is no pattern among multiple editions of the same text, the same cannot be said when all the texts are examined in discreet time chunks. A simple decade by decade breakdown would be simplistic for this analysis. Instead, five historical events were used to divide and examine the texts. The first event is the Roth Test of 1957 which was the first test for obscenity in the United States. The second event is the Miller Test for obscenity which was decided in 1973. The next event, 1994, represents the proliferation of the internet. 1994 marks a time in which the United States House of Representatives and Senate established websites and it was possible to order Pizza Hut online. The last even is the implementation of the Children's Internet Protection Act (CIPA) in 2000.

Using the historical breakdown, an interesting distribution in the appearance of keywords is established. It was expected that the number of texts with keywords would increase over time, 
reflecting the overall increase of works with sexual themes in the mainstream culture, but this was not the case. While the three pre-Roth Test texts all mention at least one of the key terms, the post-Roth period starts a significant decline. The post-Roth/pre-Miller period includes seven texts, five of which have at least one of the keywords. The post-Miller/pre-1994 period includes 32 texts, but only 14 of them have any of the keywords. Appearances of the keywords starts to increase somewhat in the 1994-1999 period where seven of the 13 texts include have them. This upward trajectory continued in the post-2000 period with 19 of the 30 texts having the keywords.

Insert Figure 1 here

The recent increase the number of references to sexual topics may be a response to the current cultural environment, but appearance alone is not necessarily a good thing. Many of the definitions are inaccurate, confusing or pejorative. Additionally, the data shows there is still a significant amount of silence on this topic as $46 \%$ of the texts published after 1994 do not include mention of any of the key terms. The pejorative nature, or complete absence, of many of the definitions does not help create a balanced discussion.

\section{Discussion}

As seen in Figure 1, the disparity of sexual representation within LIS educational texts persists. LIS texts should not reflect a society in which we turn away from educational and professional guidance when talking about controversial topics, and instead turn to filtering, prohibiting and shielding (Kuipers, 2006). These cultural biases trap us in our own cultural constructs of what is appropriate. Rather than deferring to these biases, a more deliberate attempt should be made to recognize and interact with the intricacies of controversial collections.

It seems only historical terms of rare use (curiosa and facetiae) can be handled in a neutral manner. Similarly, obscenity, the one term with a legal definition, seems to be handled well for the most part. Pornography and erotica, on the other hand, are treated poorly. Few texts acknowledge the cultural complexities inherent in defining these terms or recognize any of the different subgenres. In addition, pornography and erotica are often automatically labeled 'obscene.'

The ALA Code of Ethics and the Library Bill of Rights speak about the duty to provide equitable access and to resist efforts to censor library resources, but the discussion on sexual topics is often poorly handled or absent all together. Barely half of the texts analyzed contained any of the keywords. Moreover, 73\% of the collection development texts did not approach the topic in any way. In other words, almost three quarters of the texts being used to instruct North American library school students on how, when and why to order materials do not address the most difficult of collection management topics. Learning about collection development for any library requires an understanding of controversial topics. LIS students should be pushed to critically 
analyze their own perspectives and biases, those of the potential communities in which they will practice, and those of the profession as laid out in the ALA Bill of Rights, and the Code of Ethics. Similar to Busha's (1972) findings, this research shows that the LIS texts do not generally support a level of discourse on sex that would be in line with the ethical standards of the profession.

\section{Conclusion}

Collecting controversial materials, particularly those of a sexual nature, cannot be viewed as a choice between right or wrong. The cultural shift of sex into the mainstream enables us to readily interact with controversial information. The language and explicitness of what was once viewed as controversial, is now part of popular culture. "Mainstream representation has become more explicit and 'perverse' and imagery and language, which would have been classed as pornographic not very long ago, have become part and parcel of popular culture" (Attwood, p. 96, 2006). Currently, no work better exemplifies this than Fifty Shades of Grey. Beyond changing social mores, there is the professional obligation to take into consideration. If a significant role of an LIS professional is to combat censorship and one of the most highly censored topics is sex, what does it say about the profession that the materials used to teach students tread lightly on the topic if they address it at all?

The current project contributes to an area of research that remains fragmented. To encourage further work on a subject that has not received widespread attention, future research needs to focus in two directions. First, engagement with practicing librarians and LIS program instructors is crucial. Understanding how these two groups think about sexual materials and how this topic is discussed in courses including foundations and collection development, will provide greater context for the current work. Second, fully capturing the phenomenon also requires an examination of library collections to determine what kinds of works have been deemed 'acceptable' in the library. These further studies will prove useful in understanding the content and level of discourse surrounding what is inarguably one of the most controversial topics related to collection development.

\section{References}

ABC News. 2012, “ABC News Headlines”, available at: http://abcnews.go.com/blogs/headlines /2012/05/florida-county-library-lifts-ban-on-50-shades-of-grey/ (accessed 22 June 2012).

American Library Association 2002, Intellectual freedom manual, 6th Ed., American Library Association, Chicago.

American Library Association 1996, Intellectual freedom manual, 5th Ed., American Library Association, Chicago. 
Asheim, L. 1953, "Not censorship but selection", Wilson Library Bulletin, vol. 28, no. 1, pp. 6367.

Attwood, F. 2006, "Sexed up: Theorizing the sexualization of culture", Sexualities, vol. 9, no. 1, pp. 77-94.

Attwood, F. 2002, "Reading porn: The paradigm shift in pornography research", Sexualities, vol. 5, no. 1, pp. 91.

Bentley, P. 2012, “'Mummy porn' Fifty Shades Of Grey outstrips Harry Potter to become fastest selling paperback of all time”, available at: http:/www.dailymail.co.uk/news/article2160862/Fifty-Shades-Of-Grey-book-outstrips-Harry-Potter-fastest-selling-paperbacktime.html (accessed on 18 June 2012).

Broderick, D. 1962, “'Problem' Nonfiction”, Library Journal, vol. 87, pp. 3373-3378.

Busha, C.H. 1972, Freedom versus suppression and censorship: with a study of the attitudes of Midwestern public librarians and a bibliography of censorship, Libraries Unlimited, Littleton, Colo.

Cornog, M. 1991, Libraries, erotica, pornography, Oryx Press, Phoenix, Ariz.

Crook, E. 2001, "Erotica in Australian libraries: are we negligent collection managers?", Library Research, vol. 11, no. 2.

Curry, A. 1994, "American Psycho: A collection management survey in Canadian public libraries", Library \& information science research, vol. 16, no. 3, pp. 201-217.

Dilevko, J. \& Gottlieb, L. 2002, "Deep classification: pornography, bibliographic access, and academic libraries", Library Collections, Acquisitions, and Technical Services, vol. 26, no. 2, pp. 113-139.

Feipel, L.N. 1922, "Questionable Books in Public Libraries", Library Journal, vol. 47, pp. 859.

Fiske, M. 1959, Book selection and censorship: A study of school and public libraries in California, University of California Press.

Foerstel, H.N. 1997, Free expression and censorship in America: An encyclopedia, Greenwood Press, Westport, Conn.

Foucault, M. 1972, "Discourse on Language" in Archaeology of Knowledge, Pantheon, New York.

Gellatly, P. 1981, Sex magazines in the library collection: A scholarly study of sex in serials and periodicals, Haworth Press, New York.

Harrington, M.R. 2011, "Playboy@ Western Libraries", available at: http://works.bepress.com/ marni_harrington/8 (accessed 1 November, 2012). 
Hurych, J.M. \& Glenn, A.C. 1987, "Ethics in health sciences librarianship", Bulletin of the Medical Library Association, vol. 75, no. 4, pp. 342.

Kent, A., Lancour, H., Nasri, W.Z., Daily, J.E. \& Hall, C.M. 1968, Encyclopedia of library and information science, M. Dekker, New York.

Kuipers, G. 2006, "The social construction of digital danger: debating, defusing and inflating the moral dangers of online humor and pornography in the Netherlands and the United States", New Media \& Society, vol. 8, no. 3, pp. 379.

Library Research Services. 2012. "Challenged materials in Colorado Public Libraries, 20022012”, available at http://www.lrs.org/ (accessed 4 November 2012).

McLean, C., and Hull, E. 2003, "When the cops appear: Two libraries, two outcomes." Alki 19.1, 24-6.

McNair, B. 2002, Striptease culture: Sex, media and the democratization of desire, Psychology Press.

Moody, K. 2005, "Covert censorship in libraries: a discussion paper", The Australian Library Journal, vol. 54, pp. 138.

Moon, E. 1962, “'Problem' Fiction”, Library Journal, vol. 87, pp. 484-496.

Morgan, Candice D. 2001, "Liability for obscenity and pornography in providing internet access in the library." Library Administration \& Management 15.1, 17-19.

Pierce, J.B. \& Shaw, D. 2005, "Looking for love in all the wrong places: Accessing sexual and reproductive health information via the Readers' Guide to Periodical Literature", Library \& Information Science Research, vol. 27, no. 4, pp. 467-484.

Pope, M. 1974, Sex and the undecided librarian: A study of librarians' opinions on sexually oriented literature, Scarecrow Press, Metuchen, N.J.

Rickman, W. 2010, "A Study of Self-Censorship by School Librarians", School Library Research, vol. 13, pp. 1-21.

Robinson, P. 1976, The Modernization of Sex: Havelock Ellis, Alfred Kinsey, William Masters and Virginia Johnson, Harper \& Row New York.

Schrader, A.M. 1992, "A Study of Community Censorship Pressures on Canadian Public Libraries", Canadian Library Journal, vol. 49, no. 1, pp. 29-38.

Sens, J.M. 2010, "“Not I" Said the Pig: Who Defends Intellectual Freedom for Librarians?", Library Philosophy and Practice, pp. 1-4.

Serebnick, J. 1979, "A review of research related to censorship in libraries", Library Research, vol. 1, pp. 95-118. 
Siegel, J. 2007, "Let's Talk About Sex", Journal of Hospital Librarianship, vol. 7, no. 2, pp. 115.

Steinfirst, S. 1989, The young adult librarian's knowledge of and attitudes about sex, Scarecrow Press, Metuchen, N.J.

Watson, J.J. \& Snider, B.C. 1981, "Educating the Potential Self-Censor.", School Media Quarterly, vol. 9, no. 4, pp. 272-276.

WorldCat. 2012, "Search Results for Fifty Shades of Grey", available at: http://www.worldcat.org/search?qt=worldcat_org_all\&q=fifty+shades + of + grey (accessed 12 November 2012). 
Table 1

Number of Texts by Publication Decade by Type

\begin{tabular}{|c|c|c|c|c|c|}
\hline Type & $\mathbf{1 9 4 3 - 1 9 7 0}$ & $\mathbf{1 9 7 1 - 1 9 8 0}$ & $\mathbf{1 9 8 1 - 1 9 9 0}$ & $\mathbf{1 9 9 1 - 2 0 0 0}$ & $\mathbf{2 0 0 1 - 2 0 1 2}$ \\
\hline Intellectual Freedom & 1 & 2 & 3 & 3 & 6 \\
\hline Collection Development & 2 & 6 & 11 & 10 & 12 \\
\hline Glossaries & 1 & 1 & 3 & 3 & 2 \\
\hline Dictionaries & 2 & & 1 & 3 & 4 \\
\hline Encyclopaedias & 3 & & & 3 & 3 \\
\hline
\end{tabular}

15
16
17

17 
Table 2

Texts Analyzed and Inclusion of Key Terms

\begin{tabular}{|l|c|c|}
\hline \multicolumn{1}{|c|}{ Text type } & $\begin{array}{c}\text { Key Terms } \\
(\mathbf{n = 4 9 )}\end{array}$ & $\begin{array}{c}\text { No Key Terms } \\
(\mathbf{n = 3 6 )}\end{array}$ \\
\hline Intellectual Freedom & 14 & 1 \\
\hline Collection Development & 11 & 30 \\
\hline Dictionaries & 8 & 2 \\
\hline Encyclopaedias & 6 & 3 \\
\hline Glossaries & 10 & 0 \\
\hline
\end{tabular}




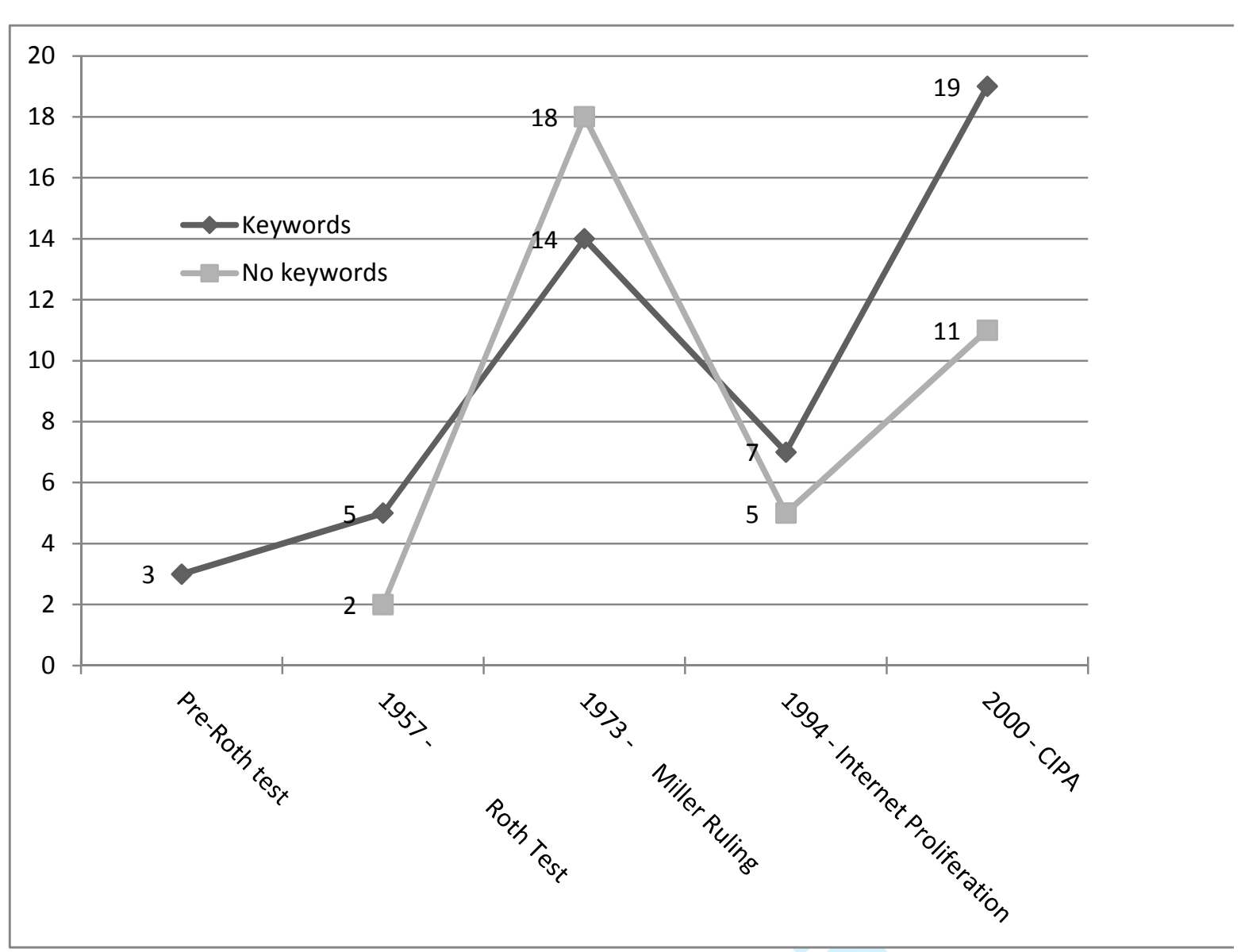

1994 -

1957 -

Keywords

No keywords
1973 - Internet 2000 Miller Ruling Proliferation CIPA

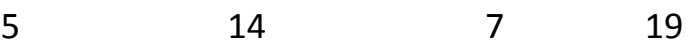

$\begin{array}{llll}2 & 18 & 5 & 11\end{array}$ 


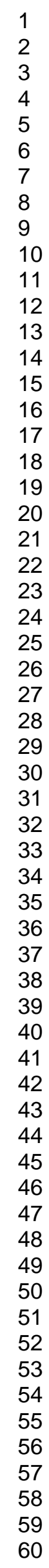

4

5

7

8

10

11

13

14

15

16

18

19

20

22

24

26

27

29

32

33

34

35

36

37

39

40

41

43

44

45

46

47

48

49

50

52

53

54

56

57

58

60 \\ Journal of Documentation}

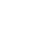

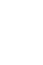

.

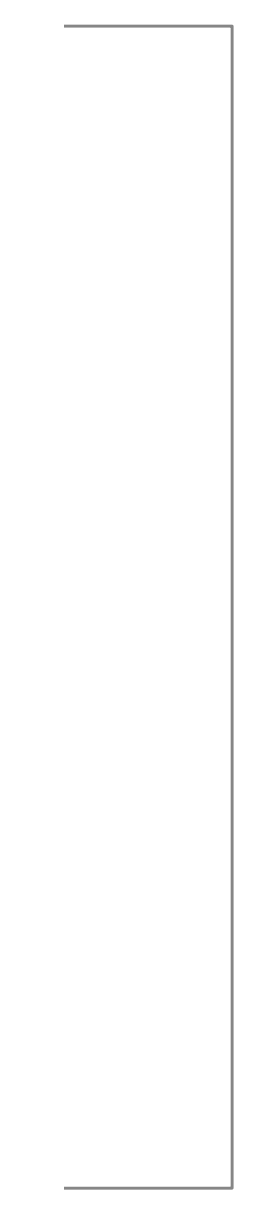

.

